\title{
Design and construction of smart grid with variable load control AC and DC with LabVIEW: off-grid
}

case.

\author{
L. Rojas-Martinez, Esp ${ }^{1}$, C. Rojas-Martinez, $\mathrm{MsC}^{2}$, L. Libis Valdez Cervantes $\mathrm{MsC}^{1}$ \\ ${ }^{1}$ Foundation University Antonio de Arevalo, Colombia,luis.rojas@unitecnar.edu.co, decano.fadi@unitecnar.edu.co \\ 2Universidad de Sucre, Colombia, claudia.rojas@unisucre.edu.co
}

\begin{abstract}
The following document will show the step-by-step development that was taken into account to carry out the design and construction of smart grid scale prototype with $A C$ and $D C$ load control through the HMI interface with LabVIEW software. The design process of the off-grid solar system was carried out through 7 stages that framed the scale of the solar installation. Once the design of the sizing was finished, programming was carried out in Human Machine Interface (HMI) graphics environment with LabVIEW software for optimal control of $A C$ and DC variable loads. This control was established through current relays from 5 volts to 110 volts $A C$ and 5 volts to 12 volts $D C$. The control interface was made through an embedded board with NI-VISA communication. It is important to note that the smart grid control prototype "Smart Grid" shows optimal results in its operation; denoting this that from the optics of the programming done in the graphics environment, the control of loads dependent on control centers; act at disposition. Redundant this in improvements for the energy consumption derived from the storage system under the autonomy designed for three days.

Keywords—LabVIEW, Load, Smart Grid, Solar photovoltaic System, Off-grid.
\end{abstract}

\section{INTRODUCTION}

Smart grids. Are electrical networks that together can have information, communication and control technologies, in order to interconnect and operate a system efficiently. Inviting system users to be part of the production chain and not just as a consumer. If not as an entity capable of becoming selfgenerating and thus be able to provide their own energy and if possible their surplus inject them into the network if it is connected to the network. The matrix of change of the technology that the smart grids carry does not only contemplate the fact of connecting, monitoring and having the best domotic for the control through communications. It is also about the change of culture that we must have if we want to disconnect from the network and stop consuming through common marketers or distributors. It is a change of mentality that will make you a citizen of the smart grids.

There are many theories, entities and authors that can emit a smart grid concept. According to Hassan Farhangin the electrical power industry is undergoing rapid change and he have talked about the path of smart grid in 2010 [1].

According to Vehbi C. Gungor, et al. The smart grid can be considered as a modern electric power grid infrastructure

Digital Object Identifier (DOI):

http://dx.doi.org/10.18687/LACCEI2019.1.1.277

ISBN: 978-0-9993443-6-1 ISSN: 2414-6390 for enhanced efficiency and reliability through automated control [2].

According to Xi Fang, Satyajayant Misra, Guoliang Xue and Dejun Yang. The idea was raised that the smart grid was considered as the network of the new generation and that it could use bi-directional flows of energy and information to create an automated electrical network [3].

Authors like Maria LorenaTuballa and Michael Lochinvar Abundob, in the review of the development of smart grid technologies present an overview of the smart grid with its general features, functionalities and characteristics [4].

Currently Colombia has an energy matrix with generation of hydraulic type, thermal with a.c.p.m, thermal with carbon, thermal with combustoleo, gas, and thermal withJet-A1. _Cogenerators with generation based on bagasse, carbon, gas, wind generation and solar generation. Showing a net effective capacity of $16856 \mathrm{MW}$.

Currently in Colombia the policies and regulatory changes have allowed to advance in types of initiatives that contemplate the use of photovoltaic solar energy. In reference [5], resolution issued by the commission of energy and gas regulation CREG 030 of 2018. By which the activities of small-scale self-generation and distributed generation in the National Interconnected System (SIN) are regulated.

Law 1715 of May 2014 [6]; in this law some guidelines about generalities and definitions are given as follows: In title 1 called "Generalities". And article 3 called "Definitions". It is called a small-scale auto-generator (AGPE); to the system that has power less than or equal to 1 MW. Similarly, the distributed generator (GD) is referred to as the entity that generates electricity near the consumption centers, and is connected to the Local Distribution System and with installed power less than or equal to $0.1 \mathrm{MW}$. Article 3 mentions nonconventional sources of renewable energy and calls them (FNCER). In this resolution it is specified in addition in title 2 called "integration to the network of self-generation and distributed generation", and article 5 called "technical standards of system availability at voltage level 1". That the sum of the installed power of the GD and AGPE must be equal to or less than $15 \%$ of the nominal capacity of the circuit. In reference [6], the law 1715 of May 13, 2014 is decreed the law through which the integration of nonconventional renewable energies to the national energy system is regulated.

$17^{\text {th }}$ LACCEI International Multi-Conference for Engineering, Education, and Technology: "Industry, Innovation, And Infrastructure for Sustainable Cities and Communities", 24-26 July 2019, Jamaica. 
It is important to note that in Chapter 2, the provisions for the generation of electricity with non-conventional energy sources (FNCE) and the efficient management of energy are dictated. A call is made to Article 8, which specifies the promotion of self-generation to small, large-scale and distributed generation through excessive delivery mechanisms, bidirectional measurement systems, sale of energy by distributed generators, sale of credit energy, mass dissemination programs and targeted outreach programs.

It should be appreciated that the changes in the laws and energy regulations in Colombia are bringing about favorable change towards the initiatives of construction of photovoltaic solar systems disconnected from the network. It is interesting to note that at this time of regulatory changes in favor of nonconventional energies and in order to bring this technology to people and show how it works, the prototype construction of a solar photovoltaic system is presented. Which contemplates within its objectives, to establish a control of variable loads depending on relays of current, activated through programmed pulses with interface of communication between LabVIEW and Maker Hub library.

The following document will be presented as follows: As a first instance, an introduction will be presented, followed by a methodological stage with the design and calculation of all elements of the solar photovoltaic system at scale. Then we will present the design of the graphic control interface developed in LabVIEW software, presented the front panel and the block diagram. Following this, a description of the stage of physical construction with its parts will be presented. Later the results of the operation, the conclusions, acknowledgments and references will be presented.

\section{Methodology Design}

\section{A. Electric Consumption}

The first stage contemplated in the design of the solar photovoltaic system [7-10] to scale is framed in the dimensioning of the loads that will be part of the prototype. In the dimensioning, AC loads and DC loads were taken into account. For the purposes of designing and starting up the design of the prototype, low-wattage loads were taken into account. See Table I. See Table II.

TABLE I

CONSUMPTION IN DIRECT CURRENT DC

\begin{tabular}{|c|c|c|c|c|c|}
\hline \multicolumn{7}{|c|}{ Consumption in direct current DC } \\
\hline Description & Number & $\begin{array}{c}\mathrm{P} \\
(\mathrm{W})\end{array}$ & $\begin{array}{c}\text { Hours / } \\
\text { day }\end{array}$ & $\begin{array}{c}\text { Days of } \\
\text { use / } \\
\text { week }\end{array}$ & $\begin{array}{c}\text { Energy (Wh / } \\
\text { week) }\end{array}$ \\
\hline Fans & 4 & 1.8 & 1 & 7 & 50.4 \\
\hline \multicolumn{7}{|c|}{ Total energy per day } & 7.20 \\
\hline \multicolumn{7}{|c|}{ Total energy DC } & 50.4 \\
\hline
\end{tabular}

TABLE II

CONSUMPTION IN ALTERNATE CURRENT AC

\begin{tabular}{|c|c|c|c|c|c|}
\hline \multicolumn{6}{|c|}{ Consumption in alternate current $\mathrm{AC}$} \\
\hline Description & Number & $\begin{array}{c}\mathrm{P} \\
(\mathrm{W})\end{array}$ & $\begin{array}{c}\text { Hours / } \\
\text { day }\end{array}$ & $\begin{array}{c}\text { Days of } \\
\text { use / } \\
\text { week }\end{array}$ & $\begin{array}{c}\text { Energy (Wh / } \\
\text { week) }\end{array}$ \\
\hline lights & 4 & 0.7 & 1 & 7 & 19.6 \\
\hline \multicolumn{5}{|c|}{ Total energy per day } & 2.80 \\
\hline \multicolumn{5}{|c|}{ Total energy AC } & 19.6 \\
\hline \multicolumn{5}{|c|}{ Total energy system week } & 70 \\
\hline \multicolumn{5}{|c|}{ Total energy system per day } & 10 \\
\hline
\end{tabular}

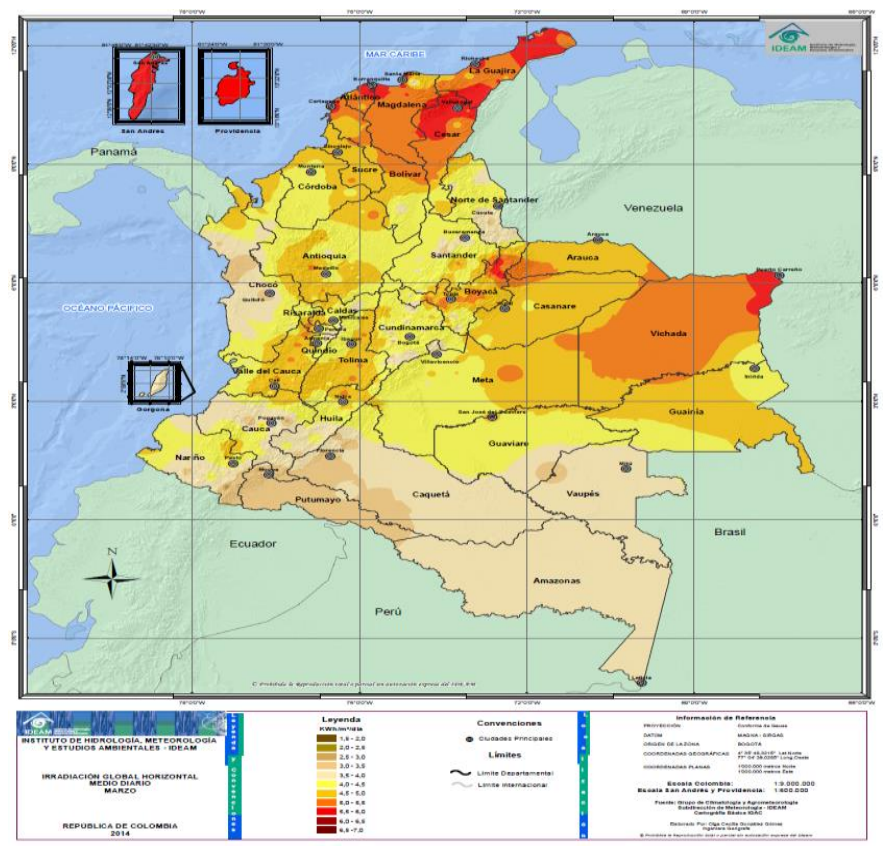

Fig. 1 Radiation captured by cities in Colombia.

\section{B. Reference Solar Pico Hours (HSP)}

Analyzing that, the solar system developed, takes as a base of location, the city of Cartagena in Colombia, it is noted that this city enjoys a high temperature during almost the twelve months of the year; with temperatures that vary from 30 to 40 degrees Celsius. and as it can be evidenced in the reference plane issued by the IDEAM, see Fig. 1, the radiation captured by cities in Colombia and in particular the solar irradiation of the city of Cartagena in the month of March, observing a variation in its space territorial between 4.5 and $6.5 \mathrm{Kwh} / \mathrm{m}$. This data is important to be able to take the reference value of the peak solar hour HSP [11]. With which the solar photovoltaic system was designed to scale. Now taking into account the above and taking as reference the irradiation of the month of March. See Fig. 2, and applying a correction factor $\mathrm{k}=0.95$ and additionally mention that the photovoltaic solar panel is under a fixed structure and this has a slope of 45 degrees. Which would indicate that in this month we would be taking advantage of its maximum energy according to the inclination.

$17^{\text {th }}$ LACCEI International Multi-Conference for Engineering, Education, and Technology: "Industry, Innovation, And Infrastructure for Sustainable Cities and Communities", 24-26 July 2019, Jamaica. 
It was estimated that in this period there is an abundance of solar irradiation and the sunset can vary between 6 and 9 hours. For purposes of validation of the design, the peak solar hours of 6.16 HSP.

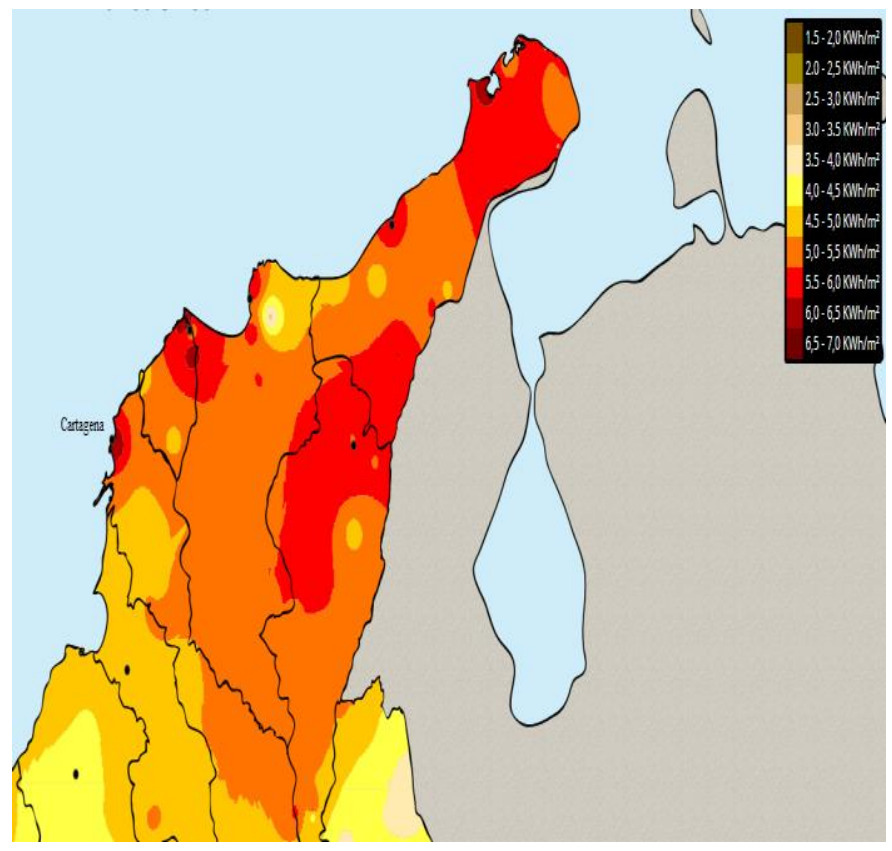

Fig. 2 Radiation captured Cartagena.

\section{Global Performance Installation}

For the calculation of the overall performance [12-14] of the installation. The individual yields of each one of the elements that are part of the solar photovoltaic system at scale were taken into account. The elements to take into account can be evidenced in Table III. And the data sheet of the photovoltaic module to be used can be evidenced in Table IV.

TABLE III

ELEMENTS AND CHARACTERISTICS

\begin{tabular}{|l|c|c|}
\hline \multicolumn{2}{|c|}{ Value of chosen constants } \\
\hline Description & Parameter & Value \\
\hline Low accumulations, without intense discharges & $K_{b}$ & 0,050 \\
\hline Inverter performance & $K_{a}$ & 0,002 \\
\hline Efficient charge controller & $K_{c}$ & 0,050 \\
\hline Losses in wiring and equipment & $K_{r}$ & 0,100 \\
\hline Battery discharged up to 60\% & $K_{v}$ & 0,150 \\
\hline $\begin{array}{l}\text { Number of days of autonomy to ensure a no- } \\
\text { load service }\end{array}$ & $P_{d}$ & 0,600 \\
\hline
\end{tabular}

Using "(1)," we calculate the overall performance of the installation.
$R=\left(1-K_{b}-K_{c}-K_{r}-K_{v}\right) *\left(\left(1-K_{a}\right) *\left(\frac{N}{P_{d}}\right)\right)$.

$R=0,6435$

Where:

$K_{b}$ : Coefficient of losses for performance in the accumulator.

$K_{a}$ : Fraction of energy that is lost by self-discharge.

$K_{c}$ : Losses for the investor's performance.

$K_{r}:$ Losses in the charge controller

$K_{v}$ : Other losses not considered previously.

$N$ : Number of days of autonomy to ensure a no-load service.

$P_{d}$ : Maximum permissible discharge depth.

Taking into account the values in Table III, it can be noted that the value of $R=0.6435$ denotes an overall performance of the installation of $64.35 \%$.

\section{Solar Panel Calculation}

In this stage of the design [15-17], the variables that we took into account and the calculation of the number of panels that are needed for the assembly of the solar photovoltaic system with an autonomy of three calendar days are presented. We needed to know the daily energy that the panels should provide, establishing a daily consumption and contrasting this with the overall performance of the installation. The daily energy that the panel was supposed to produce taking into account a selection was established.

Additionally, it was necessary to know, according to the selected panel. What was the energy produced by the system?

Using "(2)," we calculate the required energy that the panels have to supply.

Using “(3)," we calculate the energy produced per day by a photovoltaic panel.

$$
\begin{aligned}
& E D S=\frac{C D}{R G} \\
& E D S=\frac{10}{0.6435} \\
& E D S=15.54(\text { Wh } / \text { dia }) \\
& E D P=I_{p m}^{*} H S P \\
& E D P=0.56 * 6.16 \\
& E D P=3.45(\text { Ah/ paneldia })
\end{aligned}
$$


Where:

$C D$ : Total consumption per day

$R G$ : Global performance

$E D S$ : Daily energy to be produced by solar panels

$E D P$ : Energy produced per day by a photovoltaic panel

HSP : Peak Solar Hour

TABLE IV

Data Sheet of the Photovoltaic Module to be Used

\begin{tabular}{|c|c|c|}
\hline Description & Unit & Value \\
\hline$P_{\max }$ & $\mathrm{W}$ & 10 \\
\hline$V_{n o m}$ & $\mathrm{~V}$ & 12 \\
\hline$V_{p m}$ & $\mathrm{~V}$ & 17.3 \\
\hline$I_{p m}$ & $\mathrm{~A}$ & 0.56 \\
\hline$V_{o c}$ & $\mathrm{~V}$ & 21.6 \\
\hline$I_{s c}$ & $\mathrm{~A}$ & 6.13 \\
\hline
\end{tabular}

For the smart grid scale model after the enhanced calculations, it is concluded that: The number of panels needed is equal to one. Taking into account the considerations of connection forms this can be series or parallel. Using "(4)," we calculate the number of panels in series. Using "(5)," we calculate the number of panels in parallel.

$n p s=\frac{V_{s}}{V_{\text {nom }}}=\frac{12}{12}=1$.

$n p p=\left(\frac{\frac{E D S}{V_{s}}}{I_{p m} * H S P}\right)=\left(\frac{\frac{15.54}{12}}{0.56 * 6.16}\right)=0.37$.

Where:

$n p s$ : Number of panels in series

$n p p$ : Number of panels in parallel

For the construction of the solar photovoltaic system to scale, a solar panel of 10 Watts was taken into account and the current that it supplies is 0.56 Amperes (A).

\section{E. Regulator Sizing}

In this stage of the design we took into account that the charge regulator should work at the same voltage of the system and in theory should be able to support a current intensity greater than the intensity of the solar panel for assembly in an approximate value of $10 \%$ [18-19].

Knowing that the panels provide a current intensity equal to 0.56 Amperes (A) and oversized this to $10 \%$. It is obtained that the maximum intensity of the regulator is in the order of 0.62 Amperes (A). The regulator voltage is 12 volts (V).

\section{F. Storage System Calculation}

At this stage of the design of the photovoltaic solar system, the storage system is presented [20-23]. At this point we had to calculate the capacity of the battery. For this purpose we took into account data such as: Consumption, days of autonomy, voltage of the battery and depth of discharge of the battery selected for the assembly.

Knowing the Daily energy to be produced by solar panels (EDS), the days of autonomy $(\mathrm{N})$, the nominal voltage $\left(\mathrm{V}_{\text {nom }}\right)$ of the battery equal to 12 volts and taking into account a discharge of $60 \%(\mathrm{Pd})$. Using "(6)," we calculate the accumulation capacity of the batteries in Ampere Hour (Ah).

$A b b=\left(\frac{\frac{E D S^{*} N}{V_{\text {nom }}}}{\frac{P_{d}}{100}}\right)=6(A h)$.

Where:

$A b b$ : Accumulation capacity battery bank

For the development of the assembly of the equipment according to the calculations established, it is concluded that one battery is needed and this can be connected in series or parallel. For connection in specific connection was made in series.

Taking into account the previous considerations for the assembly of the battery in the scale system, the battery under reference FL1290 was taken into account with the characteristics shown in Table V.

TABLE V

SPECIFICATIONS BATTERY SERIES FL1290

\begin{tabular}{|c|c|c|}
\hline Description & Unit & Value \\
\hline Cycle use & $\mathrm{V}$ & $14.6-14.8$ \\
\hline Standby use & $\mathrm{V}$ & $13.7-13.9$ \\
\hline $\begin{array}{c}\text { Initial current Less } \\
\text { Than }\end{array}$ & $\mathrm{A}$ & 2.7 \\
\hline Vnom $_{\text {nom }}$ & $\mathrm{V}$ & 12 \\
\hline Charge & $\mathrm{Ah}$ & 9.0 \\
\hline
\end{tabular}

\section{G. Inverter Sizing}

In the final stage of the design of the solar photovoltaic system at scale, the calculation of the Inverter [24-25] was presented and for this purpose the total power of the

$17^{\text {th }}$ LACCEI International Multi-Conference for Engineering, Education, and Technology: "Industry, Innovation, And 
consumptions in alternating current was considered, estimated a total close to 2.8 watts. Now taking into account the consumption and voltage of the 12 volt system. Using (7), the minimum power of the inverter can be set to work efficiently.

$$
\begin{aligned}
& m p i=p_{a c} * 1.2 \\
& m p i=2.8 * 1.2 \\
& m p i=3.36(\mathrm{~W})
\end{aligned}
$$

Where:

$m p i$ : Minimum power of the inverter

To comply with the specifications of the design, when making the assembly of the solar photovoltaic system to scale. We took into account the inverter PI100LA. See Table VI.

TABLE VI

SPECIFICATIONS INVERTER SERIES PI100LA

\begin{tabular}{|c|c|c|}
\hline \multicolumn{2}{|c|}{ SPECIFICATIONS INVERTER SERIES PIIO0LA } \\
\hline Max. Power & Unit & Value \\
\hline High Surge Peak & $\mathrm{W}$ & 100 \\
\hline Input Voltage & $\mathrm{W}$ & 200 \\
\hline Output Voltage & $\mathrm{V}$ & 12 \\
\hline Frequency & $\mathrm{Hz}$ & 110 \\
\hline Fuse & $\mathrm{A}$ & 60 \\
\hline Output Wave Form & & 10 \\
\hline Power up To & $\mathrm{A}$ & Modified Sine Wave \\
\hline
\end{tabular}

\section{CONTROL LOAD SYSTEM}

Finished the dimensioning of the solar system to scale. We present the design of the graphic programming for the control of variable loads. To give emphasis to this process, the Block Diagram is presented, followed by the Front Panel develop in LabVIEW [26-31]. The communications and control interface for the sending and receiving of data was made through LabVIEW with arduino and Maker Hub [30, 3233].

\section{A. Block Diagram}

Finished the dimensioning of the solar system to scale. We present the design of the graphic programming for the control of variable loads. To give emphasis to this process, the Block Diagram is presented, followed by the Front Panel.

In the development of the programming for the control of variable loads AC and DC, it is established as a starting point. Use graphic programming blocks embedded with Maker Hub library and LINX communications. To start the programming cycle, an open point and a close point are established. To establish iterative cycles within the programming for load control, it is established to use a while loop structure.

On the other hand, taking into account that the real system includes 4 AC loads and four DC loads. A matrix of 8 inputs and 8 outputs was created that were controlled by a Digital Write N Chanel. It is made clear that a serial port reading input is included in the input of the programming cycle, which will be monitoring the signal coming from the board. This reading input is normally works at 9600 baud per second and the reading input will be made through the ports com and lpt of the laptop that will act as HMI screen. The graphic programming established through the Block Diagram of LabVIEW software is presented in Fig. 3.

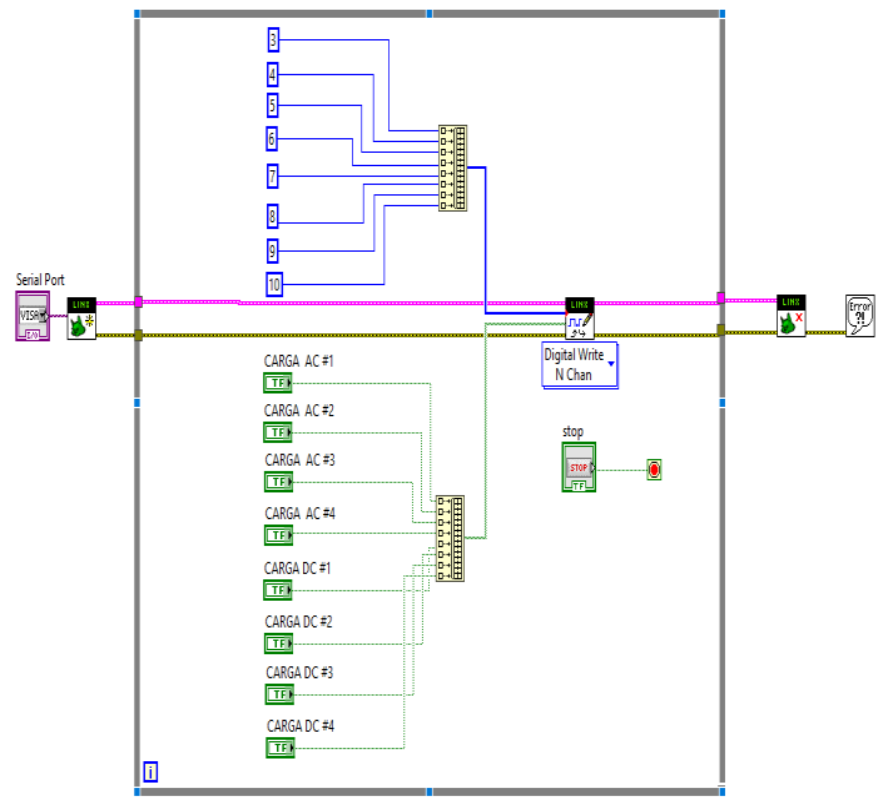

Fig. 3 Block Diagram load control system.

\section{B. Front Panel}

For the development of the control graphic environment, a man machine interface (HMI) was created in the LabVIEW programming software.

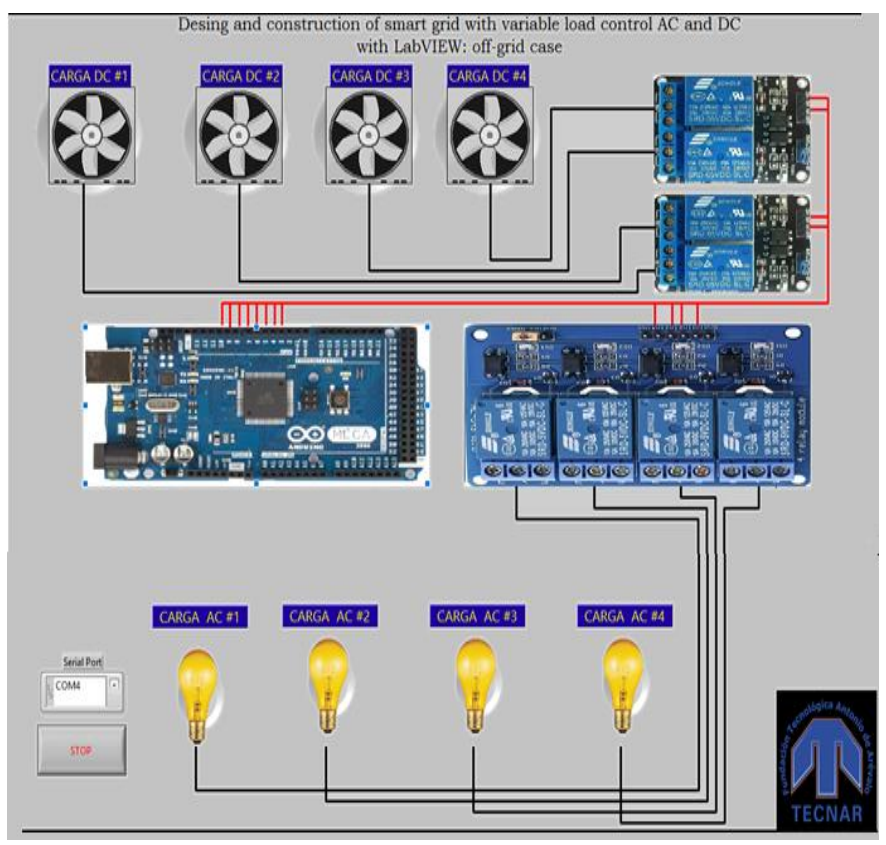

Fig. 4 Front Panel load control system.

$17^{\text {th }}$ LACCEI International Multi-Conference for Engineering, Education, and Technology: "Industry, Innovation, And Infrastructure for Sustainable Cities and Communities", 24-26 July 2019, Jamaica. 
This environment allowed us to create a variable load control like the one observed in Fig. 4. In this we can observe an embedded board named Arduino Mega 2560, a relay system for AC load control (lighting) and a relay system for control of DC loads (fans). The graphical control system of loads to relays of current accentuates its serial communication with the PC through the COM4 port. In the same way an emergency stop stage like STOP is created.

This graphic design look like the frontal image of the prototype already built, see Fig. 5 .

\section{CONSTRUCTION PROCEDURE}

For the stage of physical construction of the prototype of solar photovoltaic system to scale, a rectangular container of $40 \times 20 \times 20 \mathrm{~cm}$ was built. On the upper base of the container, the 10-watt photovoltaic solar panel is supported at 45 degrees. On the front face of the model, is the control system. Where you can see the board, the AC loads (bulbs), the current relays, fuse protection system and wiring. On the left side face, there are DC loads (fans). On the back side is the regulator. Finally, in the internal part of the container, the connections with the battery and the inverter are immersed. See Fig. 5.

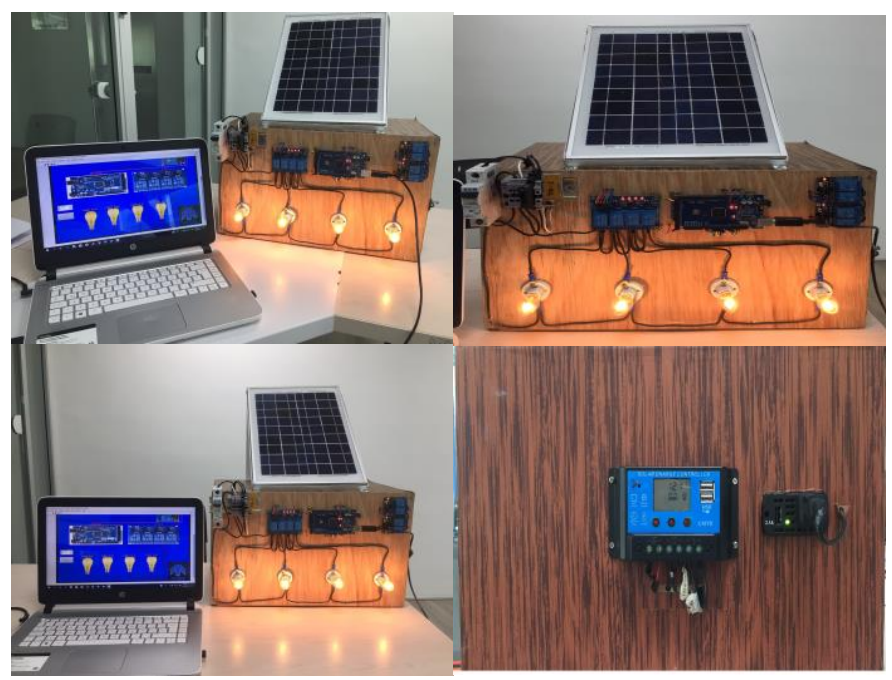

Fig. 5 Different view prototype.

\section{RESULT}

When performing solar system control tests at scale in offgrid mode. A $100 \%$ functionality is evidenced, establishing a control of optimal loads at the end of the graphical interface provided by the LabVIEW software. The response times of the control signal when the pulse is made is close to 0.3 seconds.

After the tests, it can be established that the autonomy of three days stipulated within the design is met, remaining charge even in the battery. For this purpose, the consumption of the AC and DC loads was taken into account, considering one hour of use for three days.
As for the design of the graphic programming for the control of the loads. It is established that the loads can be controlled at the disposal of the person who operates the system. The software is under a communication interface with NIVISA and link with Maker Hub library.

Regarding the use of the current relays, it is specified that with only one relay the current range of the $4 \mathrm{AC}$ loads and the 4 DC loads could be supported. This type of assembly is carried out in order to separate each element of the system and show the control strategy in terms of communication.

\section{CONCLUSIONS}

The scale design of the photovoltaic solar system complies with the stipulated design and for its optimal control, we implemented a 53-chanel digital control embedded system. This system controls only 8 charges, which stipulates that the system can be expanded to control 53 individual loads, whether AC or DC. The system is controlled through pulses intermediated by current relays. The system is currently efficient for educational use in order to demonstrate the control of loads through low cost interfaces. The project will present improvements in terms of monitoring electrical signals of voltage and power to perform an analysis of the quality of service. For this purpose, a signal processing with the wavelet transform will be carried out.

Taking into account the learning process for students in the area of industrial electricity and electronic engineering, it is specified that the design of the HMI interface is developed in LabVIEW software. The system is working under digital command lines but in the second stage the use of analog readings is already contemplated. This prototype scale design is made to begin with the second stage of the project, which consists of signal monitoring and subsequent analysis through digital signal processing.

\section{ACKNOWLEDGMENT}

Acknowledgments are presented to the Technological Foundation Antonio de Arevalo who gave institutional endorsement for the present research project under contract project number 2018-00146. The following project is derived from the construction of the prototype and for which, in the second phase, it is envisaged to make measurements with a current sensor to later perform analyzes with Wavelet Transform. Acknowledgments are given to the MICROTEAM seedling group, which contributed to the construction.

\section{REFERENCES}

[1] H. Farhangi, "The path of the smart grid," IEEE Power and Energy Magazine, vol. 8, no. 1, pp. 18-28, February 2010.

[2] V. C. Gungor, et al, "Smart Grid Technologies: Communication Technologies and Standards," IEEE Transactions on Industrial Informatics, vol. 7, no. 4, pp. 529-539, November 2001.

[3] X. Fang, S. Misra, G. Xue, D. Yang, "Smart Grid - The New and Improved Power Grid: A Survey", IEEE Communications Surveys \& Tutorials, vol. 14, pp. 944-980, December 2011. 
[4] M. L. Tuballa, M. L. Abundo, "A review of the development of Smart Grid technologies", Renewable and Sustainable Energy Reviews, vol. 59, pp. 710-725, June 2016.

[5] Ministry of Mines and Energy, CREG. (2010, Feb, 26). By which the activities of small-scale self-generation and distributed generation in the National Interconnected System are regulated [Online]. http://apolo.creg.gov.co/Publicac.nsf/1c09d18d2d5ffb5b05256eee00709c 02/83b41035c2c4474f05258243005a1191? OpenDocument

[6] Congress of the Republic. (2014, May, 13). By means of which regulates the integration of non-conventional renewable energies to the National Energy System [Online]. http://www.secretariasenado.gov.co/senado/basedoc/ley_1715_2014.html

[7] M. R. Patel, Wind and Solar Power Systems, Design, Analysis, and Operation, 2nd. Ed. Florida: CRC Press Taylor \& Francis Group, 2006.

[8] S. R. Wenhan, M. A. Green, M. E. Watt, R. Corkish, A. Sproul, Applied Photovoltaics, 3rd. Ed. London: Routledge, 2013.

[9] T. Markvart, L. Castañer, Practical handbook of photovoltaics fundamentals and applications, UK: Elsevier, 2003.

[10]C. Niucã, G. Chiriac, C. I. Gatu, D. Cuciureanu, I. Murgescu, "Laboratory Off-Grid Photovoltaic System with Two Axes Orientation", 2018 International Conference and Exposition on Electrical And Power Engineering (EPE), Romania, pp. 0846-0849, October 2018.

[11]M. P. Martinez, I. C. M. Rodriguez, E. Castro, "The hour equivalent solar pick: Definition and interpretation," Ingenieria Energetica, vol. 38, no. 2, pp.124-131, August 2017.

[12]T. P. Chang, "Performance evaluation for solar collectors in Taiwan," Energy, vol. 34, no. 1, pp. 32-40, January 2009.

[13] R. Rüther, M. M. Dacoregio, "Performance assessment of a $2 \mathrm{Kw}$ grid-connected, building-integrated, amorphous silicon photovoltaic installation in Brazil," Progress in Photovoltaics: Research and Applications, vol. 8, no. 2, pp. 257-266, May 2000.

[14] D. L. King, M. A. Quintana, J. A. Kratochvil, D. E. Ellibe, B. R. Hansen, "Photovoltaic module performance and durability following long-term field exposure," Progress in Photovoltaics: Research and Applications, vol. 8, no. 2, pp. 241-256, May 2000.

[15]E. R. Zuhal, S. Marangozoglu, "New Design for Solar Panel Tracking System Based on Solar Calculations," 2018 IEEE 61st International Midwest Symposium on Circuits and Systems (MWSCAS), Canada, pp.1042-1045, August 2018.

[16]H. Terzioglu, F. A. Kazan, M. Arslan, "A New Approach to the Installation of Solar Panels," 2015 2nd International Conference on Information Science and Control Engineering, China, pp. 573-577, April 2015

[17]K. U. Tahera, R. Fabiha, Md. Z. R. Khan, "Solar Photovoltaic System Design for a Residential Hall in BUET," 2018 10th International Conference on Electrical and Computer Engineering (ICECE), Bangladesh, pp. 1-4, December 2018.

[18]N. Efkarpidis, T. D. Rybel, J. Driesen, "Optimal placement and sizing of active in-line voltage regulators in Flemish LV distribution grids," 2015 International Conference on Renewable Energy Research and Applications (ICRERA), Italy, pp. 408-413, November 2015.

[19] H. Lee, P.K.T. Mok, K. N. Leung, "Design of low-power analog drivers based on slew-rate enhancement circuits for CMOS low-dropout regulators," IEEE Transactions on Circuits and Systems II: Express Briefs, vol. 52, no. 9, pp. 563-567, September 2005.

[20]J. Johnsson, "Sizing Batteries for Photovoltaic Systems," INTELEC '87 The Ninth International Telecommunications Energy Conference, Sweden, pp. 139-142, June, 1987.

[21]S. Jogunuri, R. Kumar, D. Kumar, "Sizing an off-grid photovoltaic system (A case study)," 2017 International Conference on Energy, Communication, Data Analytics and Soft Computing (ICECDS), India, pp.2618-262, June 2018.

[22] Y. Yang, H. Li, A. Aichhorn, J. Zheng, M. Greenleaf, "Sizing Strategy of Distributed Battery Storage System With High Penetration of Photovoltaic for Voltage Regulation and Peak Load Shaving," IEEE Transaction on Smart Grid, vol. 5, no. 2, pp. 982-991, September 2013.
[23]P. G. Nikhill, D. Subhakar, "Sizing and Parametric Analysis of a StandAlone Photovoltaic Power Plant," IEEE Journal Photovoltacis, vol. 3, no. 2, pp. 776-784, March 2013.

[24] A. Khare, S. Rangnekar, "Optimal sizing of a grid integrated solar photovoltaic system," IET Renewable Power Generation, vol. 8, no. 1, pp. 67-75, January 2014.

[25] M. Bazrafshan, N. Gatsis, E. Dall'Anese, "Placement and Sizing of Inverter-Based Renewable Systems in Multi-Phase Distribution Networks," IEEE Transactions on Power Systems, vol. 34, no. 2, pp. 918-930, September 2018.

[26] A. Gasmelseed, "New Development Environment for Modern Bioelectromagnetics Signal Processing Applications [Application Notes]," IEEE Microwave Magazine, vol. 14, no. 5, pp. 134-1352, July 2013.

[27]F. J. Jimenez, F. R. Lara, M. D. Redel, "API for communication between Labview and Arduino UNO," IEEE Latin America Transactions, vol. 12 no. 6, pp. 971-976, September 2014.

[28] J. Chacon, H. Vargas, G. Farias, J. Sanchez, S. Dormido, "EJS, JIL Server, and LabVIEW: An Architecture for Rapid Development of Remote Labs," IEEE Transactions on Learning Technologies, vol. 8, no. 4, pp. 393-401, January 2015.

[29] T. R. de Melo, J. J. da Silva, J. S. da Rocha, "Implementation of a Decentralized PID Control System on an Experimental Platform Using LabVIEW," IEEE Latin America Transactions, vol. 15, no. 2, pp. 213218, February 2017.

[30] R. M. Shrenika, S. S. Chikmath, A. V. R. Kumar, Y. V. Divyashree, R. K. Swamy, "Non-contact Water Level Monitoring System Implemented Using LabVIEW and Arduino," 2017 International Conference on Recent Advances in Electronics and Communication Technology (ICRAECT), India, pp. 306-309, October 2017

[31] A. El Hammoumi, S. Motahhir, A. Chalh1, A. El Ghzizal, A. Derouich, "Real-time virtual instrumentation of Arduino and LabVIEW based PV panel characteristics," IOP Conference Series: Earth and Environmental Science, vol. 161, no. 1, pp. 1-11, 2018.

[32] A. Tong-on, P. Saphet, M. Thepnurat, "Simple Harmonics Motion experiment based on LabVIEW interface for Arduino," Journal of Physics: Conference Series, vol. 901, no. 1, pp. 1-6, 2017.

[33] W. Alhalabi, "Patient monitoring at home using 32-channel costeffective data acquisition device," Telematics and Informatics, vol. 35, no. 4, pp. 883-891, July 2018.

$17^{\text {th }}$ LACCEI International Multi-Conference for Engineering, Education, and Technology: "Industry, Innovation, And Infrastructure for Sustainable Cities and Communities", 24-26 July 2019, Jamaica. 